\title{
Insulin-induced iron loading in the rat brown adipose tissue: histochemical and electron-microscopic study
}

\author{
A. Korấ, * M. Verêt, * V. Davidovi $\hat{E}^{\circ}$ \\ *Institute of Zoology, Faculty of Biology, 'Institute of Physiology and Biochemistry, Faculty of Biology, \\ University of Belgrade, Yugoslavia
}

(C)2003, European Journal of Histochemistry

In the present study we have reported an iron-loading in the rat brown adipose tissue (BAT) after 3-day treatment with insulin (4 lU/kg). Light microscopy showed numerous ironpositive cells (Perls' stain) mainly macrophages and brown adipocytes, while electron-microscopic examination revealed lipofuscin granules and phagosomes as iron-containing components. These results clearly indicate that iron participates in damaging of brown adipocytes.

Key words: insulin, iron, brown adipose tissue, rat, histochemistry, electron microscopy.

Correspondence: Dr. Aleksandra Korac, Institute of Zoology, Faculty of Biology, Studentski trg 16, 11000 Belgrade, Yugoslavia. Phone: international +381.11.182805. Fax: international +381.11. 638500 .

E-mail: sankor@bf.bio.bg.ac.yu

Paper accepted on March 12, 2003

European Journal of Histochemistry

2003; vol. 47 issue 3 [Jul-Sept]: 241-244
Insulin stimulates the uptake and accumulation of iron in isolated fat cells (Davis et al., 1986) increasing the number and distribution of transferrin receptors on the cell surface (Tanner and Lienhard, 1987). Transferrin receptors colocalize with glucose transporters within intracellular vesicles in 3T3-L1 adipocytes (Tanner and Lienhard, 1989; Ramm et al., 1994). Thus, in response to insulin, the transferrin receptors are recruited to the adipocyte plasma membrane together with glucose transporters (Tang et al., 1998). As we have recently shown, high dose of insulin (4 IU $/ \mathrm{kg}$ ) applied to rats for 3 days induces massive glucose uptake and accumulation of glycogen in brown adipocytes (Korac et al., 2000). The aim of the present study was to examine correlation between hyperinsulinemia and iron accumulation in BAT.

It is also known that iron may acts as co-factor in potentiating of the cell injury. Modest tissue concentration of iron induces lipid peroxidation and accumulation of damaged macromolecules (Powell and Yapp, 2000). But, exess iron is extremely harmful and may even promote cell death (Halliwell and Gutteridge, 1999). Our previous results have revealed that hyperinsulinemia causes either lipofuscin accumulation (Korac et al., 1998) or apoptosis of brown adipocytes (Korac et al., 1999). This was the reason to analyse the type and ultrastructural features of iron-containing cells, in the light of relation between iron accumulation in BAT and tissue damage.

\section{Materials and Methods}

\section{Experimental animals and design}

Male rats of Wistar strain (Rattus norvegicus) weighing 200-210 g were used for the experiments. The animals were born at and acclimated to $22 \pm$ $1^{\circ} \mathrm{C}$. They were maintained under intermittent $12 \mathrm{~h}$ periods of light and dark and were given commercial rat food (Subotica, Yugoslavia) and tap water ad 


\section{libitum.}

The rats were divided into two groups, each consisting of six animals. The first group was treated intraperitoneally with insulin (ICN Galenika, Belgrade) at a dose of $4 \mathrm{IU} / \mathrm{kg}$ body mass, over 3 days (one injection daily). The second group was injected with $0.9 \%$ saline $(1 \mathrm{~mL} / \mathrm{kg})$ in the same manner as the first group and served as control. Three hours after the last injections, all animals were killed by decapitation with a guillotine (Harvard Apparatus, USA). The interscapular portion of their BAT was removed and processed for light and electron microscopy.

\section{Light microscopy}

A half portion of BAT was fixed for 48 hours in neutral buffer solution containing $10 \%$ formaldehyde. After fixation, the tissue was routinely processed, embedded in paraffin and $5 \mathrm{~mm}$ thick sections were obtained. For staining with Prussian blue (Perls' reaction), the sections were incubated in freshly prepared mixtures of $2 \%$ potassium ferrocyanide and $2 \%$ hydrochloric acid for $15 \mathrm{~min}$. They were washed well in water and counterstained with $0.1 \%$ nuclear fast red for 5 min. The sections were then washed again in water, dehydrated, cleared and mounted in DPX. The sections were examined by Leica (Germany) light microscope.

\section{Electron microscopy}

The remaining half of BAT was cut into small pieces, were fixed in $2.5 \%$ glutaraldehyde in $0.1 \mathrm{M}$ phosphate buffer $(\mathrm{pH} 7.2)$ and postfixed in $1 \%$ osmium tetroxide in the same buffer. The specimens were dehydrated through serial alcohol solutions of increasing concentration, and were embedded in Araldite (Fluka, Germany). The blocks were trimmed and cut with glass knives on an LKB III ultramicrotome (Broma, Sweden). The thin sections were mounted on copper grids, stained either with uranyl acetate and lead citrate or unstained and examined with a Philips MC 12 electron microscope.

\section{Results}

In BAT of insulin treated rats, staining with Prussian blue was observed in phagocytic cells (macrophages) situated in the interstitium and in brown adipocytes (Figure lb). Staining was strong and cytoplasmatic. In some brown adipocytes fine
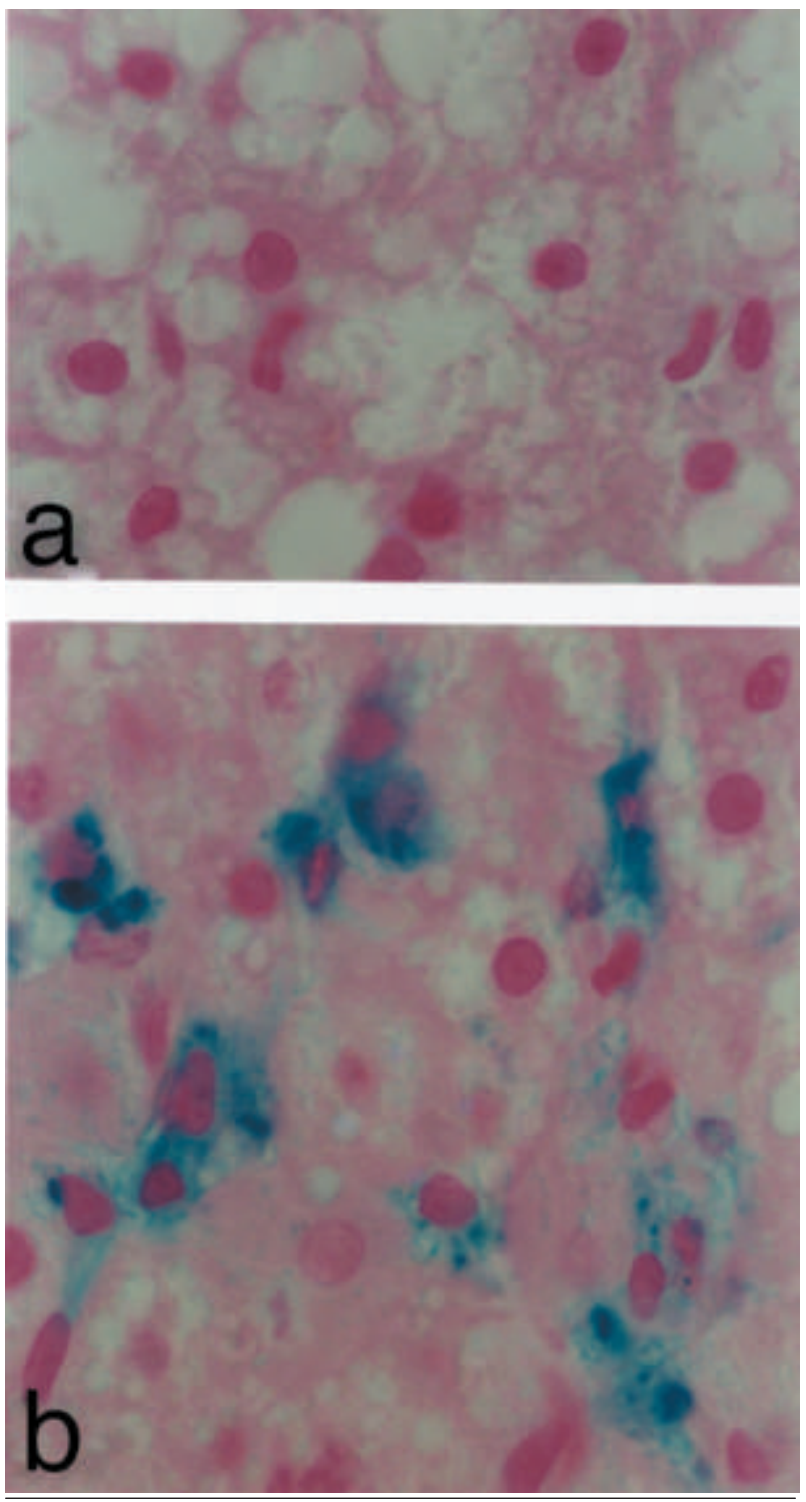

Figure 1. Staining with Prussian blue of brown adipose tissue (BAT) in control (a) and insulin treated rats (b). Iron-positive (blue) deposits are present in the cytoplasm of the majority of macrophages and brown adipocytes after insulin treatment (b). No staining was observed In BAT of control rats (a).

blue granules were also observed. By contrast, none of the sections from BAT of control rats were stained with Prussian blue (Figure 1a).

Electron microscopy confirmed deposition of iron in BAT of insulin treated rats (Figures $2 a, b$ ). In the macrophages electron-dense, iron-positive granules were observed mainly in the lysosomal compartment. This was especially notable in the lipofuscin granules (Figure 2a) which corresponded to the blue iron-positive granules on the light microscope 


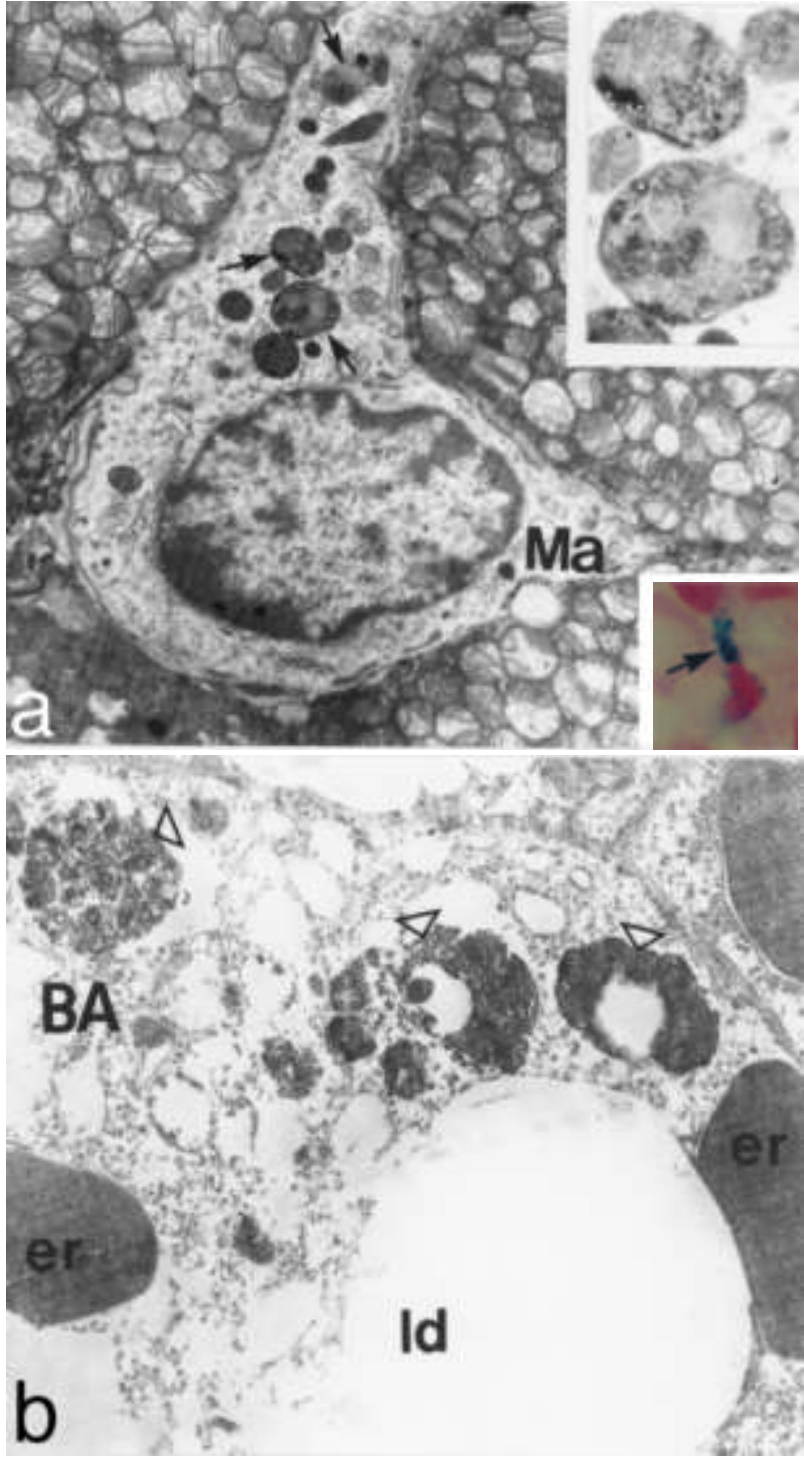

Figure 2. Electron micrographs of macrophage (a, Ma) and brown adipocyte (b, BA) from insulin treated rats. Note the numerous lipofuscin $(\rightarrow)$ in the macrophage cytoplasm which corresponds to blue, iron-positive granules $(\rightarrow$, a-lower right insert). On unstained sections, electron-dense and iron-containing particles are visible (a-upper right insert). In the brown adipocyte (b, BA) osmiophilic aggregates (open triangles) are located near phagocytozed erythrocytes (er). Some of the aggregates partly enclose small lipld droplets (Id). The aggregates have no limiting membrane and appear embedded in the cytoplasm. There are several other abnormalities alterations, namely, the cytoplasm of brown adipocytes appears disrupted and there is loss and distortion of mitochondria. Magnification: Figure 1. (a, b)- $\times 100$, orig.; Figure 2. (a)- $\times 7600$; (a-upper right insert)- $\times 22400$; (a-lower right insert)- $\times 100$, orig.; (b)- $\times 10850$.

(Figure $2 \mathrm{a}$-insert, lower right). On unstained section lipofuscin granules had electron-dense particles (Figure 2a-insert, upper right).

Some of the iron-positive brown adipocytes also showed lipofuscin which corresponded to the fine cytoplasmatic blue granules (not shown here). The majority of iron-positive brown adipocytes showed signs of the erythrophagocytosis and serious damage of organelles (Figure 2b). Namely, the cytoplasm of brown adipocytes appeared disrupted, and loss and distortion of mitochondria were obvious. Large aggregates with electron opaque cores were visible and they appeared free in the cytoplasm in the vicinity of phagocytosed erythrocytes. Two of three observed aggregates were associated with a small lipid droplet, partly enclosing it.

\section{Discussion}

BAT dysfunction is a commonly observed feature in several animal models for obesity and diabetes (Himms-Hagen, 1990; Lowell et al., 1993). Although hyperinsulinemia is also part of those metabolic syndrome diseases (Rothwell and Stock, 1988; Cusin et al., 1992), the exact molecular events linking insulin and BAT dysfunction are poorly understood.

The observation presented herein provides information on iron-accumulation in rat BAT after 3day treatment with high dose of insulin. Using Prussian blue, the specific histochemical staining for iron (Perls' reaction), we have observed iron deposition in macrophages and brown adipocytes, suggest that hyperinsulinemia induces accumulation of iron in BAT.

Electron microscopic examination of unstained thin sections is more sensitive method than Perl's reaction for identifying storage iron. Therefore we were able to analyze through both techniques for identification of storage cells and the type of ironaggregation. The electron microscopic examination of the former disclosed iron-containing particles mainly in the lipofuscin of brown adipocytes and macrophages.

The origin of lipofuscin is still controversial. Several investigators have regarded lipofuscin as an end product of molecular damage of cell organelles by oxygen free radicals (Tappel, 1975; Sohal et al., 1989), a process enhanced by iron. Namely, increased iron level could predispose the cell to oxidative stress. In addition, lipid peroxidation is stimulated by a wide range of iron complexes and certain membrane-associated structures can be considered as targets of iron-induced peroxidative damage: mitochondria, cytoplasmatic membranes and lysosomes (Peters et al., 1977; Britton et al., 
1987). Since brown adipocytes are extremely rich in mitochondria the observed appearance of lipofuscin in these cells could be ascribed to iron-mediated mitochondrial damage. Knowing the fact that mitochondria have a central role in cell death regulation (Kroemer et al., 1998), it could be predicted that hyperinsulinemia causes cumulative mitochondrial damage leading to apoptosis. By phagocyting apoptotic bodies, interstitial macrophages accumulate iron-riched lipofuscin, as we have observed.

Nakoe et al. (2001) reported intriguing evidence that most of apoptotic cells in the diaphragm muscle of dystrophic mice contain accumulated lipofuscin. We found that hyperinsulinemia induces brown adipocytes apoptosis (Korac et al., 1999), but we have not established yet a direct relationship between apoptosis and lipofuscin accumulation. Besides, no literature data, to the best of our knowledge, indicate this relationship in BAT.

The finding that erythrophagocytotic brown adipocytes are iron-positive and contain large osmiophilic aggregates is of special interest. Since brown adipocytes are capable for erythrophagocytosis (Radovanovive et al., 1996) iron-positive aggregates seem to be, at least partly, products of erythrophagosomal degradative pathway. Collectively, our previous results and those presented here suggest that iron appears to play an important role in BAT damaging caused by hyperinsulinemia, which leading to BAT dysfunction.

\section{Acknowledgements}

This study was supported by Serbian Ministry of Science, Technology and Development (Grant 1550).

\section{References}

Britton RS, Bacon BR, Recknagel, RO. Lipid peroxidation and associated hepatic organelle dysfunction in iron overload. Chem Phys Lipids 1987;45:207-39.

Cusin I, Rohner-Jeanrenaud F, Terrettaz J, Jeanrenaud B. Hyperinsulinemia and its impact on obesity and insulin-resistance. Int J Obes Relat Metabol Disord 1992;16 Suppl 4:S1-S11.
Davis RJ, Corvera S, Czech MP. Insulin stimulates cellular iron uptake and causes the redistribution of intracellular transferrin receptors to the plasma membrane. J Biol Chem 1986;261:8708-11.

Halliwell B, Gutteridge JMC. Free radicals in biology and medicine. Oxforfd University Press; New York. 1999.

Himms-Hagen J. Brown adipose tissue thermogenesis: role in thermoregulation, energy regulation and obesity. In: Thermoregulation: Physiology and Biochemistry. Shönbaum $E$, Lomax $P$, editors. Pergamon Press; New York. 1990. p. 327-414.

Korac A, Radovanovic J, Davidovic V, Koko V, Nedeljkovic M. Lipofuscinogenesis in brown adipocytes induced by insulin. An electron microscopic study. In: Proceedings of the 14th International Congress on Electron Microscopy, Cancun (Mexico). Institute of Physics Publishing, Dirac House, Bristol, UK, 1998. p. 577-8.

Korac A, Radovanovic J, Davidovic V, Koko V, Nedeljkovic M. Apoptosis in the rat brown adipose tissue after insulin treatment. J Therm Biol $1999 ; 24: 461-5$.

Korac A, Radovanovic J, Davidovic V. Glycogen-containing vesicles, vacuole and multivesicular body in the brown adipocyte. In: Proceedings of EUREM 12, Brno, (Czech Republic), Vol. 1 Biomedical sciences, 2000, p. B245-B6.

Kroemer G, Dallaporta B, Resche-Rigon M. The mitochondrial death/life regulator in apoptosis and necrosis. Ann Rev Physiol 1998;60:619-42.

Lowell BB, S-Susulic V, Hamann A, Lawitts JA, Himms-Hagen J, Boyer BB, et al. Development of obesity in transgenic mice after genetic ablation of brown adipose tissue. Nature 1993;366:740-2.

Nakae Y, Stoward PJ, Shono M, Matsuzaki T. Most apoptotic cells in mdx diaphragm muscle contain accumulated lipofuscin. Histochem Cell Biol 2001;115:205-14.

Peters TJ, Selden C, Seymour CA. Lysosomal disruption in the pathogenesis of hepatic damage in primary and secondary hemochromatosis. In: Iron Metabolism, Ciba Foundation Symposium 51. Elsevier-Excerpta Medica-North Holland; Amsterdam: 1977. p. 317-25.

Powell LW, Yapp TP. Hemochromatosis. Clin Liver Dis 2000;4:211-28.

Radovanovic J, Korac A, Davidovic V, Koko V, Todorovic V. Erythrophagocytosis by brown adipocytes of rat interscapular tissue. Histol Histopathol 2000;1:573-81.

Ramm GA, Britton RS, 0'Neill R, Bacon BR. Identification and characterization of a receptor for tissue ferritin on activated rat lipocytes. J Clin Invest 1994;94:9-15.

Rothwell NJ, Stock MJ. Insulin and thermogenesis. Int $\mathrm{J}$ Obesity 1988; 12:93-102.

Sohal RS, Marzabadi MR, Galaris D, Brunk UT. Effect of ambient oxigen concentration on lipofuscin accumulation in cultured rat heart myocytes: a novel in vitro model of lipofuscinogenesis. Free Radical Biol Med 1989;6:23-30.

Tang S, Lu B, Fantus IG. Stimulation of 125I-transferrin binding and $59 \mathrm{Fe}$ uptake in rat adipocytes by vanadate: treatment time determines apparent tissue sensitivity. Metabolism 1998;47:630-6.

Tanner LI, Lienhard GE. Insulin elicits a redistribution of transferrin receptors in 3T3-LI adipocytes through an increase in the rate constant for receptor externalization. J Biol Chem 1987;262:8975-80.

Tanner LI, Lienhard GE. Localization of transferrin receptors and insulin-like growth factor II receptors in vesicles from 3T3-LI adipocytes that contain intracellular glucose transporters. J Cell Biol 1989;108:1537-45.

Tappel AL. Lipid peroxidation and fluorescent molecular damage to membranes. In: Pathobiology of Cell Membranes. Trump BF, Arstila AU, editors. Academic; New York: 1975. p. 145-72. 